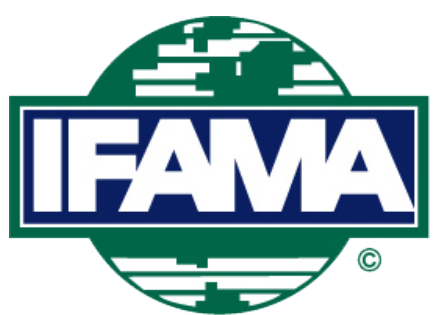

International Food and Agribusiness Management Review

Volume 23, Issue 5, 2020; DOI: 10.22434/IFAMR2019.0152

Received: 19 September 2019 / Accepted: 9 February 2020

Special issue: New and sustainable food and agribusiness management models

\title{
Blockchain-based agri-food supply chain management: case study in China RESEARCH ARTICLE
}

\author{
Hao Fu ${ }^{\mathrm{a}}$, Cuiping Zhao ${ }^{\oplus \mathrm{b}}$, Chuanxing Cheng ${ }^{\mathrm{b}}$ and Hengyun $\mathrm{Ma}^{\mathrm{b}}$ \\ ${ }^{a}$ PhD candidate, ${ }^{b}$ Professor, College of Economics and Management, Henan Agricultural University, \\ No.15, Longzi Lake College Park, Zhengzhou Eastern New District, Zhengzhou 450000, China P.R.
}

\begin{abstract}
The fundamental purpose of agri-food supply chain management is to restrict opportunism caused by information asymmetry. Traditional Chinese agri-food supply chain management introduces a contract mechanism and a trust mechanism to manage the uncertainty of the agri-food quasi-organization. However, it is almost impossible to improve the efficiency of transactions and maintain agri-food supply chain stability in the case of asymmetric information. Nowadays, blockchain, Internet of Things technology and big data drive the agri-food supply chain into a vast smart network which would break the information constraints. This paper analyzes the coupling between blockchain-based digital system and the agri-food supply chain. In addition, this paper presents two cases from China, indicating that the proposed blockchain-based system can achieve disruptive transformation in agri-food supply chain management.
\end{abstract}

Keywords: agri-food supply chain, blockchain, coupling, information asymmetry, opportunism JEL code: L0, B52, O0

(1)Corresponding author: pingcuizhao@163.com 


\section{Introduction}

As the agricultural division of labor develops and agricultural products specialize, there is an increasing need for coordination along the agri-food supply chain (Escobal and Cavero, 2012). Under these circumstances, agri-food supply chain forms a network quasi-organization, whose transactions shift from traditional spot markets to more complex contractual and relational arrangements (Lucy, 2000; Sykuta and James, 2004). This quasi-organization of the agri-food supply chain involves many participants including farmers, agriculture cooperatives, and enterprises. With the deepening of the agricultural division of labor, the opportunism and bounded rationality of the participants in the agri-food supply chain leads to high transaction costs (Grover and Malhotra, 2003).

The Chinese agri-food supply chain management introduces both formal contractual mechanism and informal trust mechanism for governance (Cai and Ma, 2015; Ma and Abdulai, 2016; Niu, 2006; Tao and Zhu 2001). The Chinese agri-food supply chain generally takes the core agricultural enterprise (dragon head enterprise) as a management core for product control, information sharing, and supply chain finance (Schneider, 2016; Yu et al., 2011). However, the cooperation among participants in the Chinese agri-food supply chain is still unstable and the competitiveness of the agri-food supply chain is still weak.

Opportunism is recognized as the fundamental reason for the low degree of industrialization of small-scale farmers and the major problem that needs to be solved in the management of the agri-food supply chain (Menard and Valceschini, 2005; Valentinov, 2007). Studies by new institutional economists have shown that opportunism stems from information constraints and cognitive constraints (Grover and Malhotra, 2003; Williamson, 1985). Under the premise of information asymmetry, opportunism has inevitably become an endogenous defect in the management of an agri-food supply chain organization. Thus, how to reduce information asymmetry has become the key to suppress opportunism, to strengthen the management of the agri-food supply chain, and to maintain the stability of the agri-food quasi-organization.

With the development of technology, agricultural informatization relies on the next-generation information technologies, such as blockchain, Internet of Things, and big data, which give the agri-food supply chain a more intelligent and intensive development direction. The information constraints of agri-food supply chain management are expected to be broken under the support of the new generation of information technologies. As a technical tool for large-scale collaboration, blockchain can transform information flow, product flow, and capital flow in the supply chain through a set of network governance mechanisms such as transparent trust mechanism and intelligent contract mechanism. Thus, how to integrate the blockchain's digital governance mechanism and the agri-food supply chain governance mechanism to inhibit opportunism in agri-food supply chain management?

At present, most papers focus on the application of blockchain in the field of agriculture from the perspective of technology. For example, Tian (2016) focused on dealing with food safety issues by the data traceability of blockchain technology; Besnainou (2017) and Cant et al. (2016) committed to researching how blockchain technology is used to deal with supply chain financial problems. However, few papers analyze the integration of blockchain and agri-food supply chain from the perspective of institutional economics.

This paper attempts to study the reform of agri-food supply chain management induced by blockchain technology from the perspective of institutional economics. It also presents the Chinese cases of blockchainbased agri-food supply chain management, which form the dual logic of 'technology + institution' governance to restrict opportunism stemmed by information asymmetry.

The rest of this paper is organized as follows: Section 2 details the digital governance system of blockchain; Section 3 is an institutional analysis of the Chinese agri-food supply chain; the integration analysis of blockchain and agri-food supply chain is illustrated in Section 4; Section 5 presents case studies on Chinese 
blockchain-based agri-food supply chain management; Section 6 states the limitations of blockchain-based agri-food supply chain management; Section 7 is the contribution, limitation, and conclusion of this research.

\section{Digital governance of blockchain}

\subsection{Connotation of blockchain}

On 1 November 2008, Nakamoto (2008) published a paper entitled 'Bitcoin: a peer-to-peer cash payment system', which combines technologies of peer-to-peer (P2P), time stamp, encryption algorithm, etc., to form a blockchain technology.

In a narrow sense, blockchain is a distributed database, using the technology of hash function, timestamp, and Merkle tree to increase the time series, relevance, and credit endorsement of data; using consensus algorithm and $\mathrm{P} 2 \mathrm{P}$ technology to perform collective maintenance of databases; using cryptography algorithm to prevent data leakage and users' privacy (IBM, 2018). Blockchain technology is hailed as a trusted machine providing a new digital solution for transactions among unfamiliar or distrustful people (The Economist, 2015).

In a broad sense, blockchain is a digital institution, which consists of a set of digital rules that are digitally defined, endorsed, maintained, and executed by all node participants (Roman et al., 2016; Sinclair et al., 2016). The blockchain was originally developed to support the Bitcoin cryptocurrency network. However, with the embedment of programming applications and smart contracts, the potential of blockchain technology has far surpassed the distributed accounting system represented by Bitcoin (Swan, 2015). Currently, the blockchain has evolved into a value system with programmable assets and a commercial system with smart contract (ibid).

\subsection{Institutional arrangement of blockchain}

Different from the articles focusing on the application of blockchain technology, this paper analyzes the institutional arrangement of blockchain technology. Blockchain technology is a fusion of various technologies and theories. The integration of one or several technologies can form a certain system arrangement in the blockchain organization. In this paper, the system arrangement of blockchain is classified and described as network chain structure, transparent trust mechanism, and smart contract mechanism.

\section{- Net chain structure}

Blockchain designs efficient organization structure through $\mathrm{P} 2 \mathrm{P}$, consensus algorithm, and other technologies. The P2P network protocol of the blockchain allows the node entities of the blockchain to conduct point-topoint transactions and accounting, which helps to avoid the traditional clearing structure and improve the operational efficiency of the entire economic system (Wanghuaqun and Wutao, 2017). In addition, blockchain applies a hierarchical cloud, allowing P2P networks to run in parallel with traditional cloud databases, making the blockchain and network chain structure organization more closely matched (ibid). For example, node platform, integrated with the producers and sellers, allow the producers and sellers to have full interaction.

\section{- Transparent trust mechanism}

The combination of the asymmetric encryption, time stamp, Merkle tree, and hash function, etc., forms a blockchain data storage mode that makes the data safe, reliable, traceable, and tamper-resistant (Antonopoulos, 2014). Data transmission between blockchain nodes can be guaranteed, forming the basis of the transparent trust mechanism, which can transform the organizational trust in the traditional system. Meanwhile, the blockchain system adopts a consensus algorithm, such as PoW (Proof of Work) and PoS (Proof of Stake), to guarantee the accounting consistency when there is only one general ledger in the whole network, and each node has the same accounting rights (Swanson, 2015). The consensus algorithm allows each node 
in the system to form collective maintenance and effective collaboration (ibid). In addition, blockchain's transparent trust mechanism applies token rewards technology to refine one's reputation, which makes the trust-based reputation of organization participants quantifiable and tradable (Mao et al., 2018).

\section{- Smart contract mechanism}

Smart contract mechanism integrates programmable scripting technology, multi-signature technology, and Turing complete technology to transform the contract into a computer trading protocol which does not require intermediation, does self-verification, and automatically executes the contract terms (Cant et al., 2016). This intelligent contract mechanism can flexibly embed various data and assets to help efficient information exchange, and value transfer and asset management (ibid). Meanwhile, this intelligent contract mechanism develops some applications that match the actual trading scenario. For example, autonomous agent technology (smart Oracle) can analyze the environment, make decisions independently, and provide intelligent agents for the intelligent distributed autonomous organizations (Poon and Buterin, 2017).

It is worth mentioning that blockchain is an open source network technology. With the growth of network governance requirement and the technology development, more technologies will be integrated into the network management system based on blockchain, providing flexible and efficient institutional supply.

\section{Institutional analysis of Chinese agri-food supply chain}

From the perspective of institutional economics, supply chain, as a carrier for organizing production and division of labor, is an intermediate network organization between a completely freely competitive market and a completely hierarchical management enterprise (Grover and Malhotra, 2003; Sykuta and James, 2004; Williamson, 1975). The contract is the main activity of supply chain governance, although the incomplete contract is universal. The hybrid 'relationship contract', embedding the elements of trust, is applicable to the middle network organization (Antia and Frazier, 2001; Knack and Keefer, 1997; Williamson, 1985).

The participants of the agri-food supply chain, including farmers, agricultural product processing enterprises, wholesale and retail sellers, establish a complex network organization. According to the transaction cost theory, as long as there is information asymmetry and limited rationality, opportunistic behavior will exist (Alchian et al., 1972; Grover and Malhotra, 2003). Therefore, opportunistic behavior caused by information asymmetry and limited rationality is the fundamental problem of agri-food supply chain management. In the agri-food supply chain, it is difficult for farmers, enterprises, and other participating entities to obtain all the information of the contractual arrangement (Jill, 2005; Ma and Abdulai, 2016). The agri-food supply chain governance needs a complicated system which relies on formal contract mechanisms as well as informal trust mechanisms (Cai and Ma, 2015; Menard and Valceschini, 2005; Yu et al., 2011).

Chinese agri-food supply chain management is mostly carried out by 'dragon head enterprises' (core agri-food enterprises), who apply contractual mechanism and relational trust mechanism to harness the supply chain (Schneider, 2016; Yu et al., 2011). However, the linear hierarchy management structure, unequal contractual mechanism, and limited trust mechanism of 'dragon head enterprises' still result in many breaches (ibid). Information collection is distributed in all aspects of the supply chain. However, the information asymmetry inevitably results in contract inequality between the core companies and other participants in the agri-food supply chain (Escobal and Cavero, 2012; Guo and Jolly, 2008). In addition, with the extension of the agrifood supply chain and the increase in organizational members, the information asymmetry increases and the trust mechanism of the agri-food supply chain with 'dragon head enterprises' as the core becomes ineffective (Hau et al., 1997; Tao and Zhu, 2001). Therefore, information constraints, which lead to an inefficient supply chain, weak supply chain synergy, and lack of risk sharing, are the core problem of Chinese agri-food supply chain management. 


\section{The integration analysis of blockchain and agri-food supply chain}

Theoretically, the new institutional economics theory developed under the premise of asymmetric information. Knight (1992), Alchian and Demsetz (1972), and Williamson (1985) recognize this problem and use uncertainty, transaction frequency, asset specificity, adverse selection, and moral hazard to compensate for the incompleteness of property rights and contracts. However, with the rise of next-generation information technologies (such as blockchain, Internet of Things, big data, cloud computing, and artificial intelligence), economists should recognize information constraint and cognitive constraint will be changed and the premise of information asymmetry will be shaken. Blockchain, as an institutional technology can provide a network governance mechanism system, which effectively regulates flow of data, reduces information asymmetry, reshapes production relations, and restricts opportunism (Roman et al., 2016; Sinclair, 2016; Swan, 2015).

Practically, blockchain and agri-food supply chain have a coupling relationship from an institutional perspective. In information technology, blockchain is a new type of internet protocol, which regulates its data flow by digital network governance mechanisms (Christian and Gans, 2019). In economics and management, the agri-food supply chain is a network resource allocation quasi-organization, which is parallel to the market or hierarchical organization (Grover and Malhotra, 2003; Nassimbeni, 1998; Williamson, 1975). The blockchain and the agri-food supply chain represent the technical network and the organizational network, respectively. Thus, they are coupling in the network properties and structure. Network governance reduces information asymmetry, restricts opportunistic behavior and achieves collaboration goals through organizational design and implementation (Nassimbeni, 1998). Blockchain reduces information asymmetry through technology application and design; the agri-food supply chain reduces information asymmetry through institutional design. The blockchain and agri-food supply chain are consistent in terms of governance objectives. Thus, the digital governance mechanisms of the blockchain and the institutional arrangements of the agri-food supply chain have a coupling relationship to some extent. For example, the smart contract mechanism of the blockchain corresponds to the contractual mechanism of the agri-food supply chain; the transparent trust mechanism of the blockchain corresponds to the relational trust mechanism of the agri-food supply chain.

The difference between the digital governance mechanisms of the blockchain and the institutional arrangements of the agri-food supply chain is worth our attention. Traditional agri-food supply chain management represents the industrial governance under the context of 'people and information dialogue'; blockchainbased management represents the digital governance of 'human and data dialogue' or 'data and data dialogue' scenarios. Thus, the blockchain-based agri-food supply chain management should follow the dual logic of 'technology + institutional arrangement'. On the one hand, the blockchain-based agri-food supply chain management can better integrate with the new generation information technology (5G, big data, artificial intelligence, cloud computing, etc.), which would further break the information constraint; on the other hand, the characteristics of the blockchain (such as decentralization, reliable database, consensus algorithm, data traceability, anonymity, smart contract, etc.) can also transform the governance mechanism of the original agri-food supply chain. For example, Tian (2017) uses blockchain to establish a blockchain-based agricultural product supply chain traceability system, which restricts opportunistic behavior in the area of food safety; Lierow et al. (2017) believe that the distribution, decentralization, and P2P transaction of blockchain can reshape the collaborative system of the supply chain and improve the synergy efficiency of the supply chain.

Based on the above discussion, we have the following proposition: the blockchain-based agri-food supply chain will form the management arrangement under the dual logic of 'technology + institution', whose organizational structure, contract mechanism, and trust mechanism will be coupled and reformed. Meanwhile, the blockchain-based agri-food supply chain management can further reduce information asymmetry and restrict opportunism. 


\section{The case: blockchain-based Chinese agri-food supply chain management}

\subsection{Materials and methods}

Yin (2003) distinguishes three types of case studies: exploratory, explanatory, and descriptive case studies. The reason to use an exploratory case study is to define the questions of a subsequent study (theory building); an explanatory case study is to test the causal relationships in the hypotheses (theory testing); and the purpose of a descriptive case study is to present a complete description of a phenomenon within its context (ibid). For case selection, Yin (1993) also mentioned that researchers should select 'exemplary' cases that reflect strong, positive examples of the phenomenon of interest. In the current research, descriptive case studies are used to describe blockchain-based agri-food supply chain management. To demonstrate the reproducibility of logic and prove the theoretical generalization of the phenomenon, this research uses a multiple-case strategy to describe the phenomenon. The data was collected from two descriptive case studies of blockchain-based poultry product supply chain (Bu Bu Chicken) and blockchain-based planting agri-food supply chain (Shan Liang Taste), respectively, both conducted in mainland China. The selected two cases of this research are operated by leading companies in agriculture and blockchain field in China. Shan Liang Taste is an agricultural technology company jointly established by Zhongnan Construction (a company investing heavily in the blockchain field) and Beidahuang Group (the most mechanized farm group in China). Shan Liang Taste was frequently reported as 'China's first blockchain-based smart farm'. Bu Bu Chicken is conducted by Zhong An Technology, which is a wholly owned subsidiary of Zhong An Insurance established by Ant Financial, Tencent, and Ping An China. Therefore, these two cases are believed to be 'exemplary' or 'typical' cases whose success or failure is particularly typical for the majority of the cases under investigation. The primary source of information is gathered through the official website of the project, news reports, and onsite investigations, which assert the reliability of case study research. For these two descriptive cases, the above corresponding theoretical foundations serve as the 'descriptive theories', which are believed to be sufficient to cover the scope and depth of the subject being described.

\subsection{Case introduction}

\section{- Case one': blockchain-based poultry farming ecosystem - 'Bu Bu Chicken' project}

As the consumption level of residents increases, green and healthy dietary consumption is increasingly valued, but the traceability of agricultural products is still a common concern of consumers. In response to this problem, Zhong An Technology launched the 'Bu Bu Chicken' supply chain management project, which realized the traceability of the chicken from the farm to the table with the help of 'blockchain + Internet of Things'.

In the ' $\mathrm{Bu}$ Bu Chicken' breeding process, the supporting Internet of Things (IoT) equipment can automatically collect information, such as the position of the chicken, the movement track, the temperature and humidity of the culture environment, and upload it in real time to the blockchain-based database 'An Chain Cloud'. The whole process of the ' $\mathrm{Bu} \mathrm{Bu}$ Chicken' is recorded. Consumers can use the mobile phone app to conduct traceability anti-counterfeiting information inquiry and learn about the data of the chicken over the past 100 days, including information of location, slaughter, and transportation. Since these data are distributed, saved, and verified by a multi-party consensus algorithm, the data have sufficient credibility.

Zhong An Technology plays the role of technology support, supply chain integration, and product operation in the ' $\mathrm{Bu} \mathrm{Bu}$ Chicken' project. The specific breeding is still completed by farmers. Zhong An Technology cooperates with logistics enterprises (such as SF EXPRESS), processing plants, E-commerce platform (such as JD.com), research institutions (such as Anhui Agricultural University), and farmers by establishing a blockchain-based supply chain. On the electronic business platform SF Best Choice and JD.com, the price

\footnotetext{
${ }^{1}$ http://finance.ce.cn/rolling/201709/19/t20170919_26110630.shtml (in Chinese)
} 
of one 'Bu Bu Chicken' is \$33. At present, 'Bu Bu Chicken' has reached cooperation intentions with more than 200 farms in Anhui, Henan, Guizhou, Shaanxi, Gansu, and Hainan. Zhong An Technology expects to cooperate with 2,500 farms to use blockchain, raising chicken by 2020. Moreover, with the financial advantages of Zhong An Insurance, Zhong An Technology also provides financial services such as insurance and loan financing for farmers and enterprises. Chicken's data can be known in real time by the blockchain supply chain platform, which reduces the cost of risk control of insurance. In addition, based on transaction data and asset data on the blockchain, financial institutions can conduct risk assessments on farmers' loanlending, which make financial services more accessible to farmers.

\section{- Case two ${ }^{2}$ : 'Shan Liang Taste'- the agri-food supply chain system under the blockchain environment}

Shan Liang Taste, an agricultural technology company, integrates 'Internet of Things + blockchain + big data' to form an agri-food supply chain management platform. 'Shan Liang Taste' implements the digitization of Beidahuang Farm Group agricultural assets. The Beidahuang's grain supply chain is dismantled into 1,639 business nodes, spanning 3 farms, 9 management districts, and 33 workstations in the blockchain-based platform of Shan Liang Taste. Based on the standardized, large-scale, and mechanized production management mode of Beidahuang Farm Group, 'Shan Liang Taste' forms an autonomous agricultural system with intelligent equipment and blockchain. The harvester, logistics vehicle, drying yard, and storage processing station use a variety of IoT equipment, which can automatically obtain time information, geographic information, basic planting information, and management data. The data is directly uploaded to the blockchain system to ensure the authenticity. Meanwhile, the participants of the grain supply chain transaction (including suppliers, manufacturers, distributors, and customers) record the transaction information by the blockchain system, which ensures the security of the transaction. Under these conditions, BeiDahuang's grain supply chain has realized a comprehensive data mapping of participating entities, production, agricultural assets, and trading systems on the blockchain network platform of 'Shan Liang Taste'.

'Shan Liang Taste' developed a variety of apps in the blockchain network platform to manage the grain supply chain. 'Shan Liang Taste' issued tradable and collateralized digital planting orders corresponding to the land in the blockchain environment by using the 'Shan Liang Blockchain Food Tickets' app. Thus, the customer can book the land to produce a season of rice by generating orders online; the farmers can contract land to complete orders. In June 2018, 'Shan Liang Taste' issued a 'Shan Liang Blockchain Order' corresponding to the land via WeChat. It cost \$1,150 to book $1 \mathrm{mu}$ land (666.67 square meters). A total of $250 \mathrm{~kg}$ of rice grown on the intended land would be delivered by post four months later. The order can be crowdfunded on the internet. A total of 10 people were able book $1 \mathrm{mu}$ land through crowdfunding at a discounted price. 'Shan Liang Taste' also programmed a supply chain order contract through the 'Shan Liang Smart Contract' app, which effectively solved the trust problem. 'Shan Liang Taste' also developed the 'Shan Liang Steward' app, which standardized production services including unified breeding, unified procurement of agricultural materials, and unified production organizational planning. Combined with a financial institution, 'Shan Liang Taste' developed the 'Shan Liang Finance' app, providing supply chain partners (including farmers, traders, logistics companies, warehousing companies, and sales companies) with a full range of new financial services (including loans, agricultural insurance, tripartite payments, payment withholding, and credit inquire) based on the blockchain data assets and trading data. In addition to integrating the supply chain of production, transportation, and trading, 'Shan Liang Taste' also cooperates with Kenfeng Seed, SGS, the Ministry of Agriculture Grain Quality Inspection Center, Tencent, Heilongjiang Academy of Agricultural Reclamation, and other institutions for quality inspection and technical support. Briefly, 'Shan Liang Taste' has changed the 'production-trade-agent-terminal' hierarchical model of the traditional agri-food supply chain, upgraded the current traditional industrial process with technology, and guaranteed the quality of grain production from the source.

\footnotetext{
$\overline{2 \text { http://www.agrichains.cn/ (in Chinese) }}$
} 


\subsection{Case analysis}

\section{- Coupling analysis of the management mechanisms}

In the above case description, both 'Bu Bu Chicken' and 'Shan Liang Taste' projects have embedded blockchain management mechanisms in agri-food supply chain management. According to the discussion in the theoretical part, our case study analysis of the coupling issue of blockchain-based agri-food supply chain management is carried out in three aspects: network chain structure, trust mechanism, and contract mechanism.

Firstly, the network organization of the agri-food supply chain and the technology network based on blockchain realize the coupling of governance structure in a practical application. The traditional agri-food supply chain is a distributed network chain structure which is composed of enterprises, farmers, distributors, regulatory agencies, consumers, and other participating entities. In order to couple the need for blockchain digital management structure, 'Shan Liang Taste' disintegrates the grain supply chain into 1,639 business nodes with digital attributes and forms a mapping with blockchain network governance; 'Bu Bu Chicken', relatively simple, directly select nodes in the original supply chain from breeding to sales for digital transformation. The data platform of 'Shan Liang Taste' and 'An Chain Cloud' play the role of a data processing center in their supply chains, respectively, which matches blockchain's P2P networks more closely with supply chains' network chain structure. According to the technical principle of the blockchain, each node of the blockchain-based supply chain has a reliable complete database book. This structural coupling between the blockchain and the agri-food supply chain transforms the original 'series' management structure into a flat 'parallel' management structure (Figure 1). Each participating note can realize the direct exchange of economic elements in the blockchain-based agri-food supply chain system, which further reduces transaction costs.

Secondly, both 'Bu Bu Chicken' and 'Shan Liang Taste' projects apply the blockchain transparent trust mechanism to couple the supply chain relationship trust mechanism, which use digital algorithms trust to alternative institutional relationship trust. 'Bu Bu Chicken' and 'Shan Liang Taste' apply blockchain, Internet of Things, cloud computing, and other new generation information technologies for information collection, transmission, and processing. As a network protocol, blockchain uses asymmetric encryption, time stamp, Merkle tree, and hash function to change the data storage from 'strip data' to 'block data', which solves the problem of data storage and transfer standardization. The blockchain also uses digital consensus algorithms to solve the problem of 'double payment' and 'byzantine general' when data is transmitted between nodes (Swanson, 2015). The consensus algorithms make sure the participating nodes in the system securely conduct network transactions without any institutional credit endorsement. The main participants of the agri-food supply chain form a consistent database, which increases the cost of each entity's fraud and default. The information asymmetry problem will be greatly alleviated. Meanwhile, the blockchain uses the characteristics of token reward, data non-tamperable, credit score transaction, etc., to transform the non-quantitative relational trust

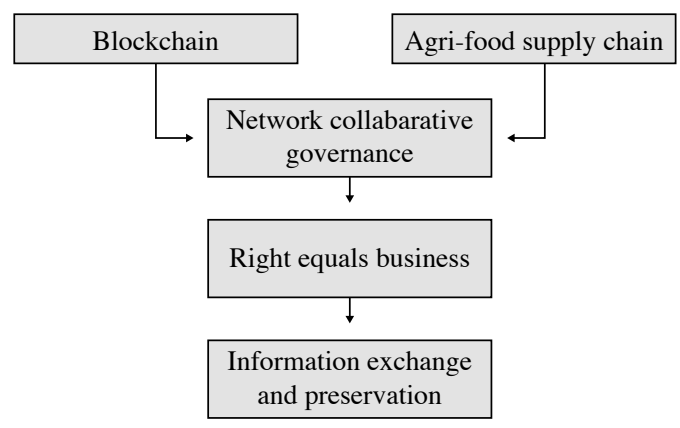

Figure 1. Blockchain and agri-food supply chain are coupled in management structure. 


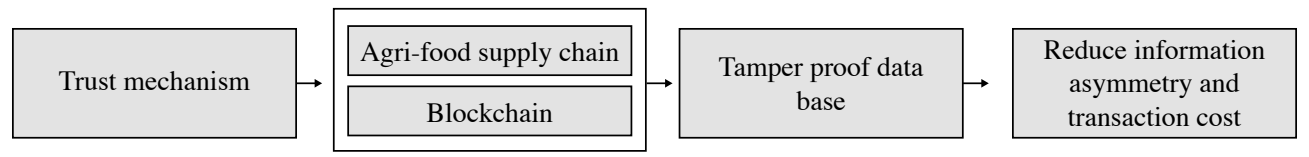

Figure 2. Blockchain and agri-food supply chain are coupled in trust mechanism

of the traditional supply chain into a digital credit which can be quantified and traded. In blockchain-based management, the transaction data of the supply chain is truly quantified and turned into the data assets and credit scores of the participating entities, which solves the problem of original relational trust decreasing with the extension of the supply chain. In the above case study descriptions, 'Bu Bu Chicken' and 'Shan Liang Taste' apply the transparent trust mechanism of blockchain to reform the traceability system of agricultural products and to establish a data-based agri-food supply chain finance system. Blockchain technology connects multiple entities of the agri-food supply chain, forming a unified database (Figure 2). Each participating entity can effectively supervise information flow, capital flow, and goods flow within the blockchain-based supply chain system. The trust mechanism with data as endorsement becomes the core mechanism of the agri-food traceability system and supply chain financial credit system.

Thirdly, the contract mechanism of the agri-food supply chain and the intelligent contract mechanism based on blockchain are coupled in the case. 'Shan Liang Smart Contract' is executed in a comprehensive, real 'human and data dialogue' environment based on blockchain, which solves the problem of contract incompleteness in traditional agri-food supply chain to some extent. Technologies such as the Internet of Things, cloud computing, and big data make it possible to comprehensively digitize the 'Shan Liang Taste' agri-food supply chain procedure in real-time online. Meanwhile, the transparent trust mechanism of the blockchain makes the supply chain form a credible and consistent database. The change of information constraints transforms the contract of a traditional agri-food supply chain into a reliable, digitally smart contract under the 'data and data dialogue' scenario. The 'Shan Liang Smart Contract' is automatically executed, reducing the risk of human operation and default, reducing the cost of contract execution, and effectively regulating the opportunistic behavior. In the blockchain-based agri-food supply chain, farmers, enterprises, consumers, and other participants can ensure the automatic execution of transactions through intelligent contracts, which contribute to the synergy and stability of the agricultural supply chain (Figure 3).

\section{- Blockchain-based agri-food supply chain management effectively constrains opportunism}

Theoretically, from the cases it can be found that opportunism is effectively constrained in the management of the agri-food supply chain based on blockchain. Williamson (1985) proposed the three factors (uncertainty, trading frequency, and asset specificity) affecting opportunism. This paper also discusses how to restrain opportunism based on blockchain technology from these three aspects.

The uncertainty of the agri-food supply chain is controllable in the blockchain environment. Firstly, market uncertainty can be controlled. Blockchain provides a trust mechanism for network organizations in the data environment, making demand-driven production possible (corresponding to the blockchain-based future products proposed by 'Shan Liang Blockchain Food Tickets'). Secondly, the production uncertainty of the agri-food supply chain is controllable. In the case of 'Bu Bu Chicken' and 'Shan Liang Taste', the entire

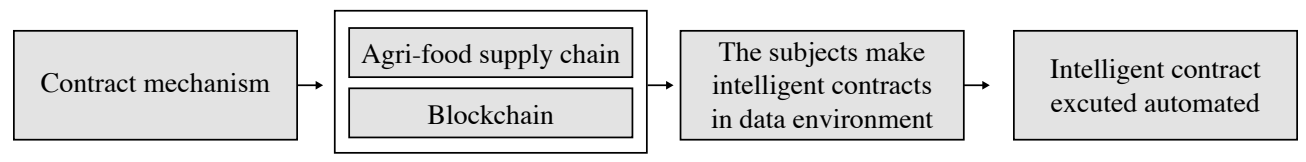

Figure 3. Blockchain and agri-food supply chain are coupled in contract mechanism. 
process of food production and marketing processes are digitized in the blockchain system, which guarantees the quantity and quality of agricultural products (corresponding to 'Shan Liang Steward'). In addition, a variety of financial services are provided in a blockchain environment to hedge production risk.

In credible data environment, the cooperative relationship of agri-food supply chain tends to be stable. Both 'Bu Bu Chicken' and 'Shan Liang Taste' map the organization network, production data, transaction data, and asset data of the supply chain on the blockchain, which form the credit endorsement for participants to integrate into the supply chain. The key of blockchain embedding lies in creating a credible ecology, which evolves a single transaction game between individuals into multiple transaction games between individuals and agri-food supply chain organizations. Therefore, the blockchain-based agri-food supply chain is no longer applicable to the single game model, but to the multiple sequential game model. The participants of the agrifood supply chain will establish long-term and stable cooperative relations in the blockchain environment.

Specific assets in data form break through the limitations of holding up. Due to the comprehensive datalization of the assets, production, trading, and relationship network in the agri-food supply chain in the blockchain, data become a new form of specific asset. The free flow and value transfer of specific assets in data form on the blockchain network break through the limitations of the original specific assets in terms of geographical aspects and trading. In the internet allocation mechanism, specific assets in the form of data can become the professional embodiment of the division of labor in the agri-food supply chain, which is expected to increase the trading opportunities in the value network based on blockchain.

\section{Limitations of blockchain-based agri-food supply chain management}

Blockchain provides an operational direction for the integrated intelligent management of the agri-food supply chain. However, the development of the blockchain is still in its infancy and there are noteworthy limitations. This research lists some limitations at technical and operational levels.

At the technical level, blockchain itself has certain limitations and needs further optimization and becomes more practical in large-scale applications. Firstly, blockchain as a distributed database, information processing is much less efficient than central database information processing. As the basis of large-scale collaboration, slow information processing will affect the overall operational efficiency, which poses a challenge to the practicality of the blockchain. Secondly, in terms of information security, the blockchain faces $51 \%$ of attacks. From the theory of blockchain technology, if someone masters more than $51 \%$ of the computing power of the entire network, data on the blockchain can be tampered with and forged. Data security issues will affect blockchain digital trust mechanism. Thirdly, blockchain lacks uniform standards in programming languages, data exchange, application programming interfaces, communication mechanisms, transaction specifications, and information security. Thus, it is difficult to build a broader ecosystem. For example, a variety of blockchain technology solutions, such as Ethereum and Ripple, have poor compatibility and interoperability.

At the operational level, the application of blockchain in the agri-food supply chain also faces some difficulties. Firstly, there are technical and cost thresholds for participants. The use of blockchain technology to innovate the agri-food supply chain model requires extensive updating of technical equipment, which will increase the input cost of the agri-food supply chain. Therefore, the traditional agri-food supply chain system and the blockchain-based agri-food supply chain system have a comparison between the input cost of technology application and the transaction cost of the system. Secondly, how to balance confidentiality with transparency would need to be worked out. Since all of the information would be out there and accessible, several contracts between organizations would need to be secured for some level of confidentiality to be retained (Charlebois, 2017). Thirdly, the institutional barriers between the current agricultural industry policies and the blockchain network governance need to be further integrated. For example, the property rights system of agricultural assets (such as farmland) and the blockchain-based agricultural property rights system need to form a unified and efficient system in aspects of registration, management, transaction, and mortgage financing. 
Blockchain technology in the agri-food supply chain has potential but still needs further research. The food industry's public leaders should embrace blockchain as an opportunity, which should be added to the digitalization strategy currently affecting the entire food industry. The most important challenge for blockchain technology is participation. For the sake of its healthy development, all parties involved should have an active attitude. A flat agri-food supply chain organization model, such as 'blockchain-based data platform + farmers' is worth exploring. Transparency, productivity, competitiveness, and sustainability of the agri-food sector could be enhanced with blockchain embedding.

\section{Contribution, limitations and conclusions}

The first major theoretical contribution of this research is to discuss the institutional arrangement of the blockchain from a 'network chain structure + trust + contract' framework to investigate how the network organization system based on the blockchain is managed. The second theoretical contribution of this article is to explore the dual management logic of 'technology + institution' for blockchain-based agricultural product supply chain, whose organizational structure, contract mechanism, and trust mechanism is coupled and reformed. The description and findings of the case analysis provide evidence to support that digital blockchain management can be coupled with the management of the agri-food supply chain. For practice, by using descriptive case studies, this research describes the possible situation of blockchain-based agrifood supply chain management from three aspects: network chain structure, trust mechanism, and contract mechanism. This research also describes the possible situation on how opportunism is effectively constrained in the management of the agri-food supply chain based on blockchain from three aspects: uncertainty, trading frequency, and asset specificity.

As with all studies, the current studies have limitations. The first limitation is the use of a descriptive case study methodology. Although descriptive case studies could provide descriptive information about the research question, they do not help understand the in-depth explanations of the phenomenon being studied. In addition, quantitative research (such as conducting large-scale survey) could provide more empirical support for the formation of propositions or configurations in the current research. The second limitation is also related to the design of the descriptive case studies. In the case description, this research cannot provide more company-specific data (such as quotation sheets, balance sheets, etc.). The major reason was that the research topic involves a level of business sensitivity, especially the relationship and contract issues, since both companies in the case study are companies in the startup stage; it is difficult to access other key informants to address the related topics. Hence, to safeguard the construct validity, future studies should invite multiple informants and collect data from multiple sources to get a richer context and deeper analysis of the current research issues.

In summary, using a descriptive case study approach, this research attempts to fill a gap in the literature on agri-food supply chain management. It introduces theories from new institutional economics, blockchain technology theory, and management fields to the agri-food supply chain context. This article is one of the few studies that explore the management mechanism coupling between blockchain and agri-food supply chain from the perspective of institutional economics. The proposed framework consisting of the abovementioned constructs is examined through two descriptive case studies. The development of next-generation information technologies such as blockchain, cloud computing, and big data is expected to further break the information constraint. Data will become a new factor of production affecting and changing the productivity and relations of the agri-food supply chain. Under the dual logic of 'technology + institution', the blockchain-based agrifood supply chain management will further break information asymmetry and restrain opportunistic behavior. The coupling of blockchain digital governance and agri-food supply chain management forms a new effective system in the three aspects of organizational structure, trust mechanism, and contract mechanism. 


\section{Acknowledgements}

This study was supported by the Chinese ministry of education humanities and social sciences research project (NO. 19YJA790121); Henan Province Philosophy and Social Science Applied Research Major Project (2019-YYZD-10); Henan Province Philosophy and Social Science Innovation Team Support Plan (2019-CXTD-03).

\section{References}

Antia, K.D. and G.L. Frazier. 2001. The severity of contract enforcement in interfirm channel relationships. Journal of Marketing 65(4): 67-81. https://doi.org/10.1509/jmkg.65.4.67.18385

Antonopoulos, A.M. 2014. Mastering bitcoin: unlocking digital cryptocurrencies. O'Reilly Media, Sebastopol, CA, USA.

Armen, A. and H. Demsetz. 1972. Production, information costs and economic organization. American Economic Review 62(50): 777-795.

Beck, R., S.C. Jacob, L. Nikolaj and M. Simon. 2016. Blockchain - the gateway to trustfree cryptographic transactions. Research Papers 153. Available at: https://aisel.aisnet.org/ecis2016 rp/153

Besnainou, J. 2017. Blockchain and supply chain financing: a conversation with Skuchain. Available at: https://tinyurl.com/ujbbpnn

Cai, R. and W. Ma. 2015. Trust, transaction costs, and contract enforcement: evidence from apple farmers in China. British Food Journal 117(10): 2598-2608.

Cant, B., A. Khadikar, A. Ruiter, J.B. Bronebakk, J. Coumaros, J. Buvat and A. Gupta. 2016. Smart contracts in financial services: getting from hype to reality. Capgemini Consulting, Paris, France. Available at: https://tinyurl.com/t9wxgf9

Catalini, C. and J.S. Gans. 2019. Some simple economics of the blockchain. Working Paper No. 22952. National Bureau of Economic Research, Cambridge, MA, USA.

Charlebois, S. 2017. How blockchain technology could transform the food industry. The Conversation. Available at: https://tinyurl.com/tjs982f

Davidson, S., P. de Filippi and J. Potts. 2016. Economics of blockchain. In: Public choice conference. March 10-12, 2016. Fort Lauderdale, FL, USA.

Escobal, J.A. and D. Cavero. 2012. Transaction costs, institutional arrangements and inequality outcomes: potato marketing by small producers in rural Peru. World Development 40(2): 329-341.

Grover, V. and M.K. Malhotra. 2003. Transaction cost framework in operations and supply chain management research: theory and measurement. Journal of Operations Management 21(4): 457-473.

Guo, H. and R.W. Jolly. 2008. Contractual arrangements and enforcement in transition agriculture: theory and evidence from China. Food Policy 33(6): 570-575.

Hobbs, J.H. 2005. Information, incentives and institutions in the Agri-food sector. The Canadian Journal of Agricultural Economics 51(3): 413-429. https://doi.org/10.1111/j.1744-7976.2003.tb00183.x

IBM. 2018. Crypto anchors and blockchain. IBM Research. Available at: www.research.ibm.com/5-in-5/ crypto-anchors-and-blockchain

Jarosz, L. 2000. Understanding agri-food networks as social relations. Agriculture and Human Values 17(3): 279-283.

Knack, S. and P. Keefer. 1997. Does social capital have an economic payoff? A cross-country investigation. Quarterly Journal of Economics 112: 1251-1288.

Knight, J. 1992. Institutions and social conflict. Cambridge University Press, Cambridge, UK.

Lee, H.L., V. Padmanabhan and S. Whang. 1997. Information distortion in a supply chain: the bullwhip effect. Management Science 50(12): 1875-1886.

Lierow, M., C. Herzog and P. Oest. 2017. Blockchain: the backbone of digital supply chains. Oliver Wyman, New York, NY, USA. Available at: https://tinyurl.com/yxye47e5

Ma, W. and A. Abdulai. 2016. Linking apple farmers to markets: determinants and impacts of marketing contracts in China. China Agricultural Economic Review 8(1): 2-21. 
Mao, D., Z. Hao, F. Wang and H. Li. 2018. Innovative blockchain-based approach for sustainable and credible environment in food trade: a case study in Shandong Province China. Sustainability 10: 3149.

Menard, C. and E. Valceschini. 2005. New institutions for governing the agri-food industry. European Review of Agricultural Economics 32(3): 421-440.

Nakamoto, S. 2008. Bitcoin: a peer-to-peer electronic cash system. Available at: https://bitcoin.org/bitcoin.pdf Nassimbeni, G. 1998. Network structures and co-ordination mechanisms. International Journal of Operations and Production Management 18(6): 538-554.

Niu, R.F. 2006. Industrialized management of agriculture in China: observations and comments. Issues in Agricultural Economy 3: 8-15.

Poon, J. and V. Buterin. 2017. Plasma: scalable autonomous smart contracts. Available at: https://plasma.io/

Schneider, M. 2016. Dragon head enterprises and the state of agribusiness in China. Journal of Agrarian Change 17(1): 3-21.

Swan, M. 2015. Blockchain: blueprint for a new economy. O'Reilly Media, Inc., Sebastopol, CA, USA.

Swanson, T. 2015. Consensus-as-a-service: a brief report on the emergence of permissioned, distributed ledger systems. Available at: https://tinyurl.com/le39hyd

Sykuta, M. and H.S. James. 2004. Organizational economics research in the US agricultural sector and the contracting and organizations research institute. American Journal of Agricultural Economics 86(3): 756-761.

Tao, Z. and Zhu, T. 2001. An agency theory of transactions without contract enforcement: the case of China. China Economic Review 12: 1-14.

The Economist. 2015. Blockchains - The great chain of being sure about things. The Economist, London, UK. Tian, F. 2016. An agri-food supply chain traceability system for China based on RFID \& blockchain technology. In: $13^{\text {th }}$ International Conference on Service Systems and Service Management (ICSSSM). June 24-26, 2016. Kunming University of Science and Technology, Kunming, China.

Tian, F. 2017. A supply chain traceability system for food safety based on HACCP blockchain \& internet of things. In: $14^{\text {th }}$ International Conference on Service Systems and Service Management (ICSSSM). June 16-18, 2017. Dalian, China, pp. 1-6.

Valentinov, V. 2007. Why are cooperatives important in agriculture? An organizational economics perspective. Journal of Institutional Economics 3: 55-69.

Wanghuachun and Wutao. 2017. Cryptography in blockchain. Journal of Nanjing University of Posts and Telecommunications (natural science edition) 6: 61-67. https://doi.org/10.14132/j.cnki.16735439.2017.06.010

Williamson, O.E. 1975. Markets and hierarchies: analysis and antitrust implications. A study in economics of internal organizations. Free Press, New York, NY, USA.

Williamson, O.E. 1985. The economic institutions of capitalism: firms, markets relational contracting. Free Press, New York, NY, USA.

Yin, R.K. 1993. Applications of case study research. Sage Publications, Beverly Hills, CA, USA.

Yin, R.K. 2003. Case study research: design and methods, $3^{\text {rd }}$ edition. Sage Publications, Thousand Oaks, CA, USA.

Yu, X., D. Abler and C. Peng. 2011. Dancing with the dragon heads: enforcement, innovations and efficiency of contracts between agricultural processors and farmers in China. Courant Research Centre: Poverty, Equity and Growth - Discussion Papers No. 63. University of Göttingen, Göttingen, Germany. 
